\title{
Langensteiner, Matthias, Für Land und Luthertum. Die Politik Christophs von Württemberg (1550-1568)
}

\section{Naïma Ghermani}

\section{OpenEdition}

\section{Journals}

Édition électronique

URL : http://journals.openedition.org/ifha/2206

DOI : $10.4000 /$ ifha. 2206

ISSN : 2198-8943

\section{Éditeur}

IFRA - Institut franco-allemand (sciences historiques et sociales)

Référence électronique

Naïma Ghermani, «Langensteiner, Matthias, Für Land und Luthertum. Die Politik Christophs von Württemberg (1550-1568) », Revue de I'IFHA [En ligne], Date de recension, mis en ligne le 01 janvier 2010, consulté le 22 septembre 2020. URL : http://journals.openedition.org/ifha/2206 ; DOI : https:// doi.org/10.4000/ifha.2206

Ce document a été généré automatiquement le 22 septembre 2020.

(C)IFHA 


\title{
Langensteiner, Matthias, Für Land und Luthertum. Die Politik Christophs von Württemberg (1550-1568)
}

\author{
Naïma Ghermani
}

1 Si l'histoire politique connaît actuellement un regain notamment à travers les très nombreuses études sur l'histoire culturelle du politique, l'auteur de cet ouvrage issu d'une thèse accomplie sous la direction du professeur Albrecht Luttenberger, entend proposer un autre angle d'attaque.

2 Entièrement dédié au règne d'une figure importante de l'histoire de la Réformation, le duc Christophe de Württemberg (1550-1568), ce livre imposant, fondé sur un travail considérable de dépouillement d'archives, vient combler une lacune. En effet, comme le note l'auteur dans son introduction, de très nombreuses études reconnaissent le rôle central du duc de Württemberg, cependant aucun ouvrage général et complet ne lui avait été consacré depuis la fin du XIXe siècle. Il ne s'agit cependant pas ici de proposer une biographie - les premières années avant le règne sont d'ailleurs évoquées en trois pages - mais bien d'offrir une analyse de la politique de ce prince luthérien dans ces années charnières entre l'échec de l'Intérim et le début des tensions confessionnelles, avec, entre les deux, la paix d'Augsbourg dans laquelle le prince joua un rôle actif. Toutefois, l'auteur ne prétend pas renouer avec une histoire politique des plus classiques. Il souhaite envisager son acteur principal à la lumière d'un concept forgé par son directeur de thèse et par Rudolf Vierhaus, l'idée d'un " espace d'action " (Handlungsraum) ou d'une " marge de manœuvre " (Handlungsspielraum). Précisément il s'agit d'envisager la " matrice des frontières et des possibilités de l'action politique » (p. 10), ou, en d'autres termes, d'appréhender la politique du prince comme " un système ", c'est-à-dire " un complexe d'éléments entrant en interaction " pour reprendre la définition de Talcott Parsons citée par l'auteur. Ces habits neufs de l'histoire politique ne supposent rien de moins que d'étudier les facteurs externes et internes qui président à l'action politique, les premiers renvoyant aux relations diplomatiques avec les autres princes et l'empereur, les alliances et les guerres; les 
seconds étant les motifs personnels du prince, « ses dispositions intellectuelles et ses impulsions mentales » (p. 10).

Il ne nous semble pas que ce parti pris, sous ses aspects conceptuels, diffère de beaucoup avec une histoire politique traditionnelle, il est vrai des plus solides. Ainsi, l'ouvrage suit un ordre chronologique où l'auteur distingue cinq périodes dans la politique de Christophe de Württemberg : la première, comprise entre 1550 et 1553, qui correspond aux premières années de stabilisation du pouvoir notamment par une politique neutre et modérée avec l'Empire et l'empereur ; les années 1553-1555, qui marquent le début d'une politique confessionnelle autonome ; 1556-1565, centrée davantage sur la politique intérieure du territoire, notamment la politique financière et le renforcement de l'église luthérienne wurtembergeoise, sans compter une politique active contre les divisions intra-confessionnelles ; la période 1563-1566 est marquée, quant à elle, par la confrontation avec les calvinistes du puissant voisin palatin ; une dernière partie plus brève est dédiée, enfin, aux dernières années de règne.

4 L'ouvrage permet ainsi de mettre en valeur une figure d'un prince " politique » au sens où on l'entend au XVIe siècle, recherchant la conciliation, la paix perpétuelle garante d'une légitimité pour la foi luthérienne. Son arrivée au pouvoir est d'emblée marquée par cette vision conciliatrice : il règle très vite le procès en félonie qui pesait sur son défunt père et se rapproche non seulement des territoires puissants du sud de l'Empire, la Bavière et le Palatinat, mais aussi de l'empereur Charles Quint. C'est dans la même perspective qu'il tente de fonder une ligue supraconfessionnelle, la ligue de Heidelberg, afin de préserver la paix dans l'Empire. C'est peut-être son échec qui le pousse à participer activement à la paix de religion de 1555 qui lui permet par la suite de consolider son église territoriale. Là encore, il encourage fortement l'unification du camp luthérien, divisé depuis l'Intérim, mais aussi les controverses interconfessionnelles avec les catholiques, tout comme, à la fin de son règne, il fera du combat contre le calvinisme une de ses priorités. Dès 1563, il rédige ainsi une réfutation du catéchisme de Heidelberg avant d'organiser, l'année suivante, un colloque à Maulbronn opposant les théologiens de son université de Tübingen et des théologiens palatins. Mais son action principale contre ses voisins calvinistes demeure surtout sa prise de position vigoureuse lors de la diète d'Augsbourg de 1566. Ce travail riche et solide met donc bien en lumière un de ces acteurs de la seconde moitié du XVIe siècle qui oscillent entre conciliation politique et défense des intérêts confessionnels.

Naïma Ghermani (Université Grenoble II) 